\title{
The effect of resveratrol on toxicity caused by cisplatin in rats with experimentally created diabetes by streptozotocin
}

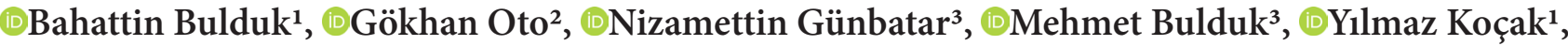 \\ (1)Sadi Elasan ${ }^{4}$ \\ ${ }^{1}$ Van Yüzüncü Yll University, Faculty of Health Sciences, Department of Physiotherapy and Rehabilitation, Van, Turkey \\ ${ }^{2}$ Van Yüzüncü Yıl University, Faculty of Medicine, Department of Pharmacology and Toxicology, Van, Turkey \\ ${ }^{3}$ Van Yüzüncü Yıl University, Faculty of Health Sciences, Department of Nursing, Van, Turkey \\ ${ }^{4}$ Van Yüzüncü Yıl University, Faculty of Medicine, Department of Biostatistics, Van, Turkey
}

Cite this article as: Bulduk B, Oto G, Günbatar N, Bulduk M, Koçak Y, Elasan S. The effect of resveratrol on toxicity caused by cisplatin in rats with experimentally created diabetes by streptozotocin. J Health Sci Med 2022; 5(1): 124-130.

\begin{abstract}
Aim: In our study, the therapeutic effect of resveratrol against the toxicity of cisplatin in rats with experimental diabetes mellitus with streptozotocin was investigated.

Material and Method: 64 rats were used in the study. 8 groups were randomly formed, with 8 rats in each group. Group 1 was determined as the control group. Group 2 (STZ) was injected with $60 \mathrm{mg} / \mathrm{kg}$ streptozotocin intraperitoneally (ip) on the first day to induce diabetes. Group 3 (RES) was given $100 \mathrm{mg} / \mathrm{kg}$ of resveratrol orally every day. Group 4 (SIS), a single dose of cisplatin $7 \mathrm{mg} / \mathrm{kg}$ (ip) was administered 3 days later. Group 5 (STZ+RES), group 6 (STZ+SIS), group 7 (RES+SIS) and group 8 (STZ+SIS+RES) were determined.

Results: While there was weight gain in the control and RES groups during the experiment, the STZ and STZ + SIS groups showed a significant decrease in body weights of the rats. In the groups given streptozotocin and cisplatin together with resveratrol, there was no decrease in body weight, but a small increase was observed. In groups with increased blood glucose values with streptozotocin, these values were found to have dropped significantly with resveratrol. The TAS level has increased significantly in groups RES, STZ+RES, SIS+RES and STZ+SIS+RES according to the control group; no significant difference has been found in the other groups compared to the control group. While the AST level was significantly higher in the STZ, SIS and STZ+SIS groups compared to the control group, the ALT level was found to be significantly higher in the STZ and STZ+SIS groups compared to the control group. Creatinine was found to be significantly higher in SIS, STZ+SIS, RES+SIS and $\mathrm{STZ}+\mathrm{SIS}+\mathrm{RES}$ groups compared to the control group. The SIS group and RES+SIS and STZ+SIS+RES groups were compared, the decrease in the RES+SIS and STZ+SIS+RES groups was statistically significant. QT (ms) values increased significantly in the STZ and STZ+SIS groups compared to the control group, but there was no significant difference in the other groups. According to the control group, the heart rate per minute was found to be significantly lower in the STZ and STZ+SIS groups. Conclusion: As a result, it was seen that the use of resveratrol would be effective in reducing the increased glucose levels in the treatment of diabetes and in the treatment of possible complications.
\end{abstract}

Keywords: Diabetes, cispilatin, resveratrol, ECG

\section{INTRODUCTION}

Diabetes is a lifelong disease that develops when the pancreas does not produce enough insulin hormone or the insulin hormone it produces cannot be used effectively. In recent years, the prevalence of diabetes mellitus has increased considerably all over the world. For this reason, many studies are carried out in this area (1).

Resveratrol is a flavonoid polyphenolic phytoalexin synthesized by plants against traumatic injury or fungal attack. Phytoalexin; It is an antibiotic produced by plants as a result of any external stress or pathogenic (fungal) attack (2).

Cisplatin is a chemotherapeutic drug used in the treatment of cancer. Unlike other antineoplastic drugs, cisplatin is a platinum derivative. It can accumulate in tissues and cause toxicity. It accumulates 5 times more in kidney tissue compared to other tissues and causes death in tubule cells (3). The most important side effect that can be encountered in the use of cisplatin is nephrotoxicity (4). 
In our study, the therapeutic effect of resveratrol against the toxicity of cisplatin in rats with experimental diabetes mellitus with streptozotocin was investigated.

\section{MATERIAL AND METHOD}

The study was carried out with the permission of Van Yüzüncüyıl University Animal Experiments Local Ethics Committee (Date: 25.06.2015, Decision 2015/08). All procedures were carried out in accordance with the ethical rules and the principles of the Declaration of Helsinki.

\section{Material}

In the study, 64 healthy rats obtained from Yüzüncü Yıl University Faculty of Medicine Experimental Research Unit were used. Before the experiment, the rats were adapted to the ambience for 7 days. Experimental applications in the study were carried out in accordance with the maintenance conditions of laboratory animals (12 hours of light, 12 hours of darkness and $22 \pm 1^{\circ} \mathrm{C}$ and $60 \%$ humidity). During the experimental applications, standard commercial rat food (pellet feed) and drinking water were given to the rats ad libitum. 8 random group was created with 8 rat in each group. The rats' weights were recorded at the beginning of the study, and rats that died during the experiment and that did not have diabetes were not included in the study.

\section{Method}

1. Group (Control): The control group was given normal pellet rat food and drinking water throughout the experiment.

2. Group (STZ): To induce diabetes, rats in this group were injected with $60 \mathrm{mg} / \mathrm{kg}$ streptozotocin (intraperitoneally) on the first day. After 3 days, blood sugars were determined with blood taken from the tail.

3. Group (RES): The rats in this group were daily administered $100 \mathrm{mg} / \mathrm{kg}$ resveratrol by oral gavage method.

4. Group (SIS): A single dose of cisplatin $7 \mathrm{mg} / \mathrm{kg}$ (intraperitoneally) was administered to the rats in this group at the end of the 3rd day.

5. Group (STZ+RES): To induce diabetes, rats in this group were injected with $60 \mathrm{mg} / \mathrm{kg}$ streptozotocin (intraperitoneally) on the first day. $100 \mathrm{mg} / \mathrm{kg}$ resveratrol was given daily by oral gavage method

6. Group $(\mathbf{S T Z}+\mathrm{SIS})$ : To induce diabetes, rats in this group were injected with $60 \mathrm{mg} / \mathrm{kg}$ streptozotocin (intraperitoneally) on the first day. Then, a single dose of cisplatin $7 \mathrm{mg} / \mathrm{kg}$ (intraperitoneally) was administered.
7. Group (RES+SIS): The rats in this group were daily administered $100 \mathrm{mg} / \mathrm{kg}$ resveratrol by oral gavage method.. Then, at the end of the 3rd day, a single dose of cisplatin $7 \mathrm{mg} / \mathrm{kg}$ (intraperitoneally) was administered.

8. Group (STZ+SIS+RES): To induce diabetes, rats in this group were injected with $60 \mathrm{mg} / \mathrm{kg}$ streptozotocin (intraperitoneally) on the first day. The rats in this group were given $100 \mathrm{mg} / \mathrm{kg}$ resveratrol daily by oral gavage method. A single dose of cisplatin $7 \mathrm{mg} / \mathrm{kg}$ (intraperitoneally) was administered 3 days later.

Streptozotocin was suspended in sodium citrate buffer ( $\mathrm{pH}: 4.5)$ and resveratrol was suspended in dimethylsulfoxide and administered to experimental animals. In the STZ treated groups, blood glucose levels were determined 3 days later by blood taken from the tail. Rats with blood glucose of $250 \mathrm{mg} / \mathrm{dl}$ and above were accepted as diabetes $(5,6)$. The study took 14 days.

\section{Electrocardiography (ECG) Shot}

After the experimental applications, the rats were anesthetized with $50(\mathrm{mg} / \mathrm{kg})$ ketamine (ip). The rats were placed on the table in the right lateral position for ECG recording. The hairs on the upper parts of the elbow and knee joints of the rats were removed and cleaned with alcohol. Electrode gel was applied to the upper part of the elbow and knee joint to facilitate current flow. Then, crocodile-mouth electrodes were placed over the elbow joint in the forelimbs and over the knee joint in the hind limbs. The ECG device was adjusted to be $1 \mathrm{mV}=10 \mathrm{~mm}$ and printing speed $50 \mathrm{~mm} / \mathrm{sec}(7)$.

\section{Taking Blood Samples}

After ECG recordings, the rats were placed on the table in the dorso-ventral position. The right hand was grasped by the neck of the rat, and the thumb and index fingers and front legs were held tightly and stretched. The hairs on the thorax were shaved, the skin was wiped with alcohol, the heartbeat point was determined with a finger, the cannula was inserted vertically at a distance of $2-3 \mathrm{~mm}$ from the left edge of the sternum in the 2nd and 3rd intercostal space, and the blood was taken with an injector. The collected blood was transferred to the tubes and centrifuged and serum and plasma were collected.

\section{Statistical Analysis}

Descriptive statistics for continuous variables in our study; Expressed as Median, Mean, Standard Deviation, Minimum and Maximum values. The Kruskal Wallis test was used to compare group means in terms of continuous variables. Duncan test was used to identify different groups. The statistical significance level was taken as $5 \%$ in the calculations and the SPSS (ver.23) statistical package program was used for the calculations. 


\section{RESULTS}

In this study, which was conducted to investigate the therapeutic effects of resveratrol in rats with experimental diabetes, the experimental animals used during the 14-day trial period were weighed on the $1^{\text {st }}$ and $14^{\text {th }}$ days. While weight gain was found in the control and RES groups during the 14 day experiment, it was determined that there was a significant decrease in the body weights of the rats in the STZ and STZ+SIS applied groups. In the groups given resveratrol together with STZ, there was no decrease in body weights, but a small increase was observed.

The blood values and ECG findings of the experimental animals are given in Figure 1. While the TAS level increased significantly in the RES, STZ+RES, SIS+RES and STZ+SIS+RES groups compared to the control group, no significant difference was found in the other groups compared to the control group. Considering the TOS values in the study, no statistically significant difference was found between the group averages. However, TOS values in all STZ applied groups increased compared to the values in the control group. Considering only the STZ applied group and the STZ+RES group, a decrease was observed in the STZ+RES group, although not statistically significant. While the AST level was significantly higher in the STZ, SIS and STZ+SIS groups compared to the control group, the difference was insignificant in all other groups compared to the control group. According to the ALT level control group, the difference between STZ and STZ+SIS groups was found to be meaningless, compared to control in all other groups. Creatinine increased significantly in SIS, STZ+SIS, RES+SIS and STZ+SIS+RES groups compared to the control group. When only the SIS group and the RES+SIS and STZ+SIS+RES groups were compared, the decrease in the RES+SIS and STZ+SIS+RES groups was statistically significant. Considering the glucose values, the increase in the STZ and STZ+SIS groups was found to be significant compared to the other groups.

QT (ms) values increased significantly in the STZ and STZ+SIS groups compared to the control group, but there was no significant difference in the other groups. Compared to the control group, the heart rate per minute was found to be significantly lower in the STZ and STZ+SIS groups. While cisplatin alone did not cause a decrease, a significant decrease was observed when administered with STZ no significant difference was found in the other groups.

\section{DISCUSSION}

It is estimated that 4 out of every 100 people in the world will have diabetes in the next 10 years due to the unhealthy diet, sedentary life and the resulting excess weight brought about by city life in recent years. Diabetes mellitus, which is caused by a combination

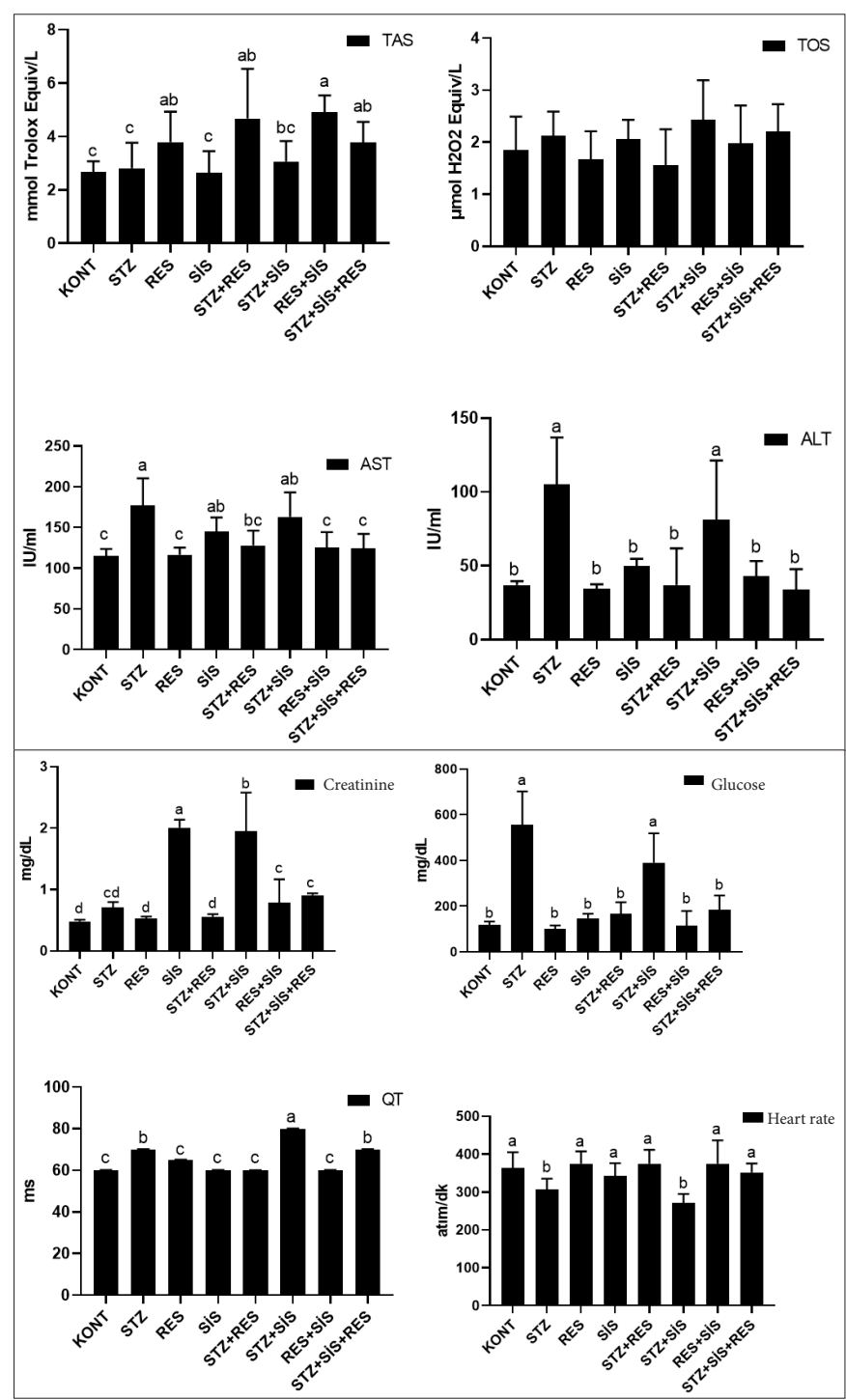

Figure 1. The results of TAS, TOS, AST, ALT, Creatinine and glucose analysis in blood samples taken from rats and QT and heart rate values according to groups in terms of ECG values.

of hereditary and environmental factors and results in an increase in blood glucose level, is a lifelong metabolic disease that causes carbohydrate, fat and protein metabolism disorders that occur as a result of the deficiency or ineffectiveness of the insulin hormone (8). Diabetes is known to damage various organs and tissues. The most important complications of diabetes are retinopathy, neuropathy and nephropathy (9). In the later stages of diabetes, glomerular and renal vascular lesions as well as acute and chronic pyelonephritis can be observed (10). Diabetes is a risk factor for heart failure. It can reveal ischemia and arrhythmias in the heart (11). The very common streptozotocin (STZ) was used to create a diabetes model in experimental animals (12). In the study of Green et al. (13), a single dose of $60 \mathrm{mg} / \mathrm{kg}$ (ip) STZ was administered in our study, since it was reported that a single dose of $40-60 \mathrm{mg} /$ $\mathrm{kg} \mathrm{STZ} \mathrm{in} \mathrm{rats} \mathrm{would} \mathrm{be} \mathrm{sufficient} \mathrm{to} \mathrm{create} \mathrm{a} \mathrm{diabetes}$ model. As it is known, nephropathy and cardiopathy 
are chronic complications of diabetes. Our work was concluded in a short period of 14 days. It was thought in our study the toxic effect of cisplatin could be benefited from in order to see the long-term damage of diabetes. The effect of resveratrol against the toxicity of both STZ and cisplatin was determined. In this study, in accordance with the literature, it was found that body weight decreased statistically significantly in the groups with diabetes (STZ, STZ+SIS) $(14,15)$. Resveratrol administration is known to slow down weight loss caused by diabetes. It is thought that body weights of rats with diabetes decreased as a result of polyuria, increased protein and lipid breakdown. It was determined that body weights that decreased with diabetes in rats did not decrease in resveratrol given treatment groups (STZ+RES and STZ+SIS+RES). In our study, the fact that RES application prevented weight loss in diabetic rats is in parallel with other studies $(16,17)$.

In the diabetic groups who received RES for treatment, the decreased glucose level was statistically significant. When the blood glucose level in the STZ+RES group at the beginning of the study was compared with the blood glucose level at the end of the study, a significant decrease was detected. The therapeutic effect of resveratrol has also been shown in similar studies $(18,19)$. Nihei et al., in 2001 in their study in rats caused the phosphorylation of GLUT4, one of the glucose transporters, by affecting the insulin receptors of resveratrol; reported that blood glucose level decreased by increasing glucose uptake into the cell (20). In another study, they stated that resveratrol decreased the plasma glucose level in diabetic rats (21). In our study, we think that resveratrol normalizes the high blood glucose level by affecting the transport systems involved in glucose transport. As a result of certain reactions in the body, harmful wastes called oxidants occur. The biological damage caused by these harmful wastes in the organism is known as oxidative stress. There are endogenous and exogenous antioxidant molecules that prevent the oxidative effects of free radicals, that is, oxidative stress in the organism. They protect cells from the damaging effects of oxidant agents. It is necessary to measure total oxidant (TOS) to determine the amount of oxidant in the body, and total antioxidant (TAS) measurement to determine the amount of antioxidant (22). In our study, TAS and TOS levels were measured in the sera obtained. While the TAS level was found to be significantly higher in the RES, STZ+RES, SIS+RES and STZ+SIS+RES groups, that is, in all groups given resveratrol, compared to the control group, no significant difference was found in the other groups compared to the control group. In a study by Rodrigo and Bosco in 2006, they reported that resveratrol has a protective effect against kidney damage due to its free radical scavenger and enzyme regulatory effect (23). In another study, it was determined that resveratrol has a protective effect against oxidative damage caused by ethanol in different organs (24). Similar studies support the antioxidant property of resveratrol in our study $(25,26,27)$. In our study, it was found that resveratrol increased TAS levels. Resveratrol is thought to protect the body against oxidative stress by eliminating the harmful effects of free radicals. Resveratrol is known to be a phytoalexin. Resveratrol is known to increase the resistance of vessels against oxidative stress by protecting endothelial cells in apoptotic cell death caused by hydrogen peroxide. It is thought that resveratrol is a natural antioxidant, inhibiting the superoxide radical that occurs in mitochondria, reducing the oxidative chain complex and inhibiting lipid peroxidation $(28,29,30)$. It has been observed that the antioxidant aspect of resveratrol is also effective in conditions that cause great biological damage to the organism, such as diabetes and cisplatin. Considering the TOS values in the study, no statistically significant difference was found between the group averages. However, TOS values in the STZ and cisplatin applied groups were higher than the values in the control group. When only the STZ applied group and the STZ + RES group were examined, it was observed that although it was not statistically significant in the STZ + RES group, a decrease was observed, and at the same time, a result closer to the control group. The higher TOS value in the STZ+SIS group compared to the STZ+SIS+RES group is thought to protect the body against oxidant damage by resveratrol. Resveratrol is thought to be a powerful antioxidant by stimulating antioxidant enzymes, and stabilizes radical derivatives due to its hydroxylated structure and prevents oxidative damage (31).

Aminotransferases (AST and ALT) are particularly known as markers of liver damage. But they are also found in the heart and skeletal muscle, as well as in the brain, pancreas, kidney, lung, and erythrocytes. While the AST level was significantly higher in the STZ, SIS and STZ+SIS groups compared to the control group, the difference was insignificant in all other groups compared to the control group. While ALT level increased significantly in the STZ and STZ+SIS groups compared to the control group, the difference was insignificant in all other groups compared to the control group. It was determined that AST and ALT levels increased significantly in the groups given STZ and SIS, while these rates decreased in the groups given RES. This showed us that resveratrol has a preventive effect on the toxic effects caused by STZ and SIS. In similar studies with resveratrol, the same effect was found (32-34). In a study by Juan et al. (35) in 2002, 
Sprague-Dawley administered resveratrol orally 20 $\mathrm{mg} / \mathrm{kg}$ per day for about a month in rats. At the end of the study, they reported that there was no significant change in ALT and AST enzyme levels. Ghosh et al. (36) in their study in 2014, reported that $60 \mathrm{mg} / \mathrm{kg} \mathrm{STZ}$ administration increased AST and ALT values, which are markers of hepatic dysfunction. They have proven that STZ causes liver damage. Yousef et al. (37) in their study in rats in 2009, showed that cisplatin caused liver damage and increased liver enzymes. In our study, we think that the administration of STZ and SIS caused liver damage, therefore the transport functions were impaired, membrane permeability changed, thus the levels of enzymes changed.

In this study, we found that resveratrol alone did not cause a change in AST and ALT values. The therapeutic effect of resveratrol was thought to be due to its regulation of the formation of inflammatory mediators by providing the oxidant and antioxidant balance. Creatinine increased significantly in SIS, STZ+SIS, RES+SIS and STZ+SIS+RES groups compared to the control group. In 2011, Alhaider et al. (38) reported that there was a significant increase in serum creatinine levels after 8 weeks in rats that they created a diabetes model with STZ. We have seen this situation in our own study. When only the SIS group and the RES+SIS and STZ+SIS+RES groups were compared, the decrease in the RES+SIS and STZ+SIS+RES groups was statistically significant. After cisplatin use, increased creatinine level, decreased clearance and electrolyte imbalance are indicators of nephrotoxicity $(3,39)$. It shows that resveratrol is effective against nephrotoxicity caused by electrolyte imbalance by regulating creatinine level.

ECG, which is a frequently used and important diagnostic method in the evaluation of heart diseases, is the process of recording the action currents that occur during the operation of the heart and are distributed over the body surface (40). The QT interval is the total time indicative of the depolarization and repolarization of the ventricles. It is determined by measuring the portion from the beginning of the QRS complex to the end of the T wave. Long QT syndrome with syncope and sudden cardiac death is a risk factor for fatal ventricular arrhythmias. Prolongation of the QT interval may cause "torsade de pointes" type ventricular arrhythmias in bradycardia and electrolyte imbalances (hypopotashemia, hypomagnesemia) (41). The prolongation of the QT interval is usually due to the prolongation in the repolarization section of the ventricles (42). In studies conducted in rats, long QT values have been reported as a sign of hypokalemia and myocardial infarction $(43,44)$. During this study, rats were anesthetized with $50(\mathrm{mg} / \mathrm{kg})$ ketamine (ip). The averages of QT values in this study show similarities with the studies performed in rats under anesthesia $(45,46)$. In our study, QT (ms) values increased significantly in the STZ and STZ+SIS groups compared to the control group, but no significant difference was found in the other groups. Resveratrol corrected QT prolongation caused by streptozotocin and cisplatin. Li-Man Hung et al. (2) reported that resveratrol has a therapeutic effect in arrhythmias after ischemia. In addition, the similarity of QT values in the group given only resveratrol compared to the control group may also be an indication that resveratrol does not cause any arrhythmia. Hashemzaei et al. (47) reported that resveratrol alone had no effect on ECG parameters and they did not find a significant result compared to the control group, confirming this information. In our study, it is thought that resveratrol has cardioprotective and arrhythmia regulating effectsThis can be explained by the fact that resveratrol reduces the amount of free radicals formed during cardiotoxicity. The results we found are similar to the literature (2,48-51).

Electrocardiogram R-R interval gives information about the heart rate. The values in the studies on heart rate in rats under anesthesia show parallelism with the values in our study $(52,53)$. In the statistical analysis, the difference of the R-R interval between the group averages in the study was found to be significant. It was determined that the R-R (sec) interval was prolonged in the STZ and STZ+SIS groups compared to the control group. Compared to the control group, the heart rate per minute was found to be significantly lower in the STZ and STZ+SIS groups. While cisplatin alone did not cause a decrease, a significant decrease was observed when administered with STZ. Vilar-Pereira et al. (54) reported in their study that resveratrol reduces prolonged PR and QTc intervals, increases heart rates and improves cardiac output. In our study, we found that resveratrol increased the low heart rate caused by STZ and SIS application and shortened the prolonged $\mathrm{R}-\mathrm{R}$ intervals, that is, brought them closer to the control group values. In a study on resveratrol, it was reported that it increased the amount of adenosine in the heart tissue (55). Adenosine is known as a cardiac protector with its effects such as normalization of cardiac functions and suppression of arrhythmias. The rhythm-regulating effect of resveratrol can be explained by increasing the amount of adenosine. In the literature review, no information was given about how it would affect the heart rate in rats given administered streptozotocin and cisplatin. More studies on the subject need to be done. 


\section{CONCLUSION}

The therapeutic effect of resveratrol on STZ and cisplatin-induced biological damage was examined.It was determined that resveratrol played a regulatory role on biochemical parameters and cardiac arrhythmias.As a result; we concluded that resveratrol prevents diabetesinduced weight loss, lowers elevated blood sugar levels, has antioxidant properties and a therapeutic effect on liver damage, lowers prolonged QT times, and regulates heart rate.We think that the use of resveratrol will be beneficial in the treatment of diabetes and tissue damage caused by cisplatin.

\section{ETHICAL DECLARATIONS}

Ethics Committee Approval: The study was carried out with the permission of Van Yüzüncüyll University Animal Experiments Local Ethics Committee (Date: 25.06.2015, Decision 2015/08).

Referee Evaluation Process: Externally peer-reviewed.

Conflict of Interest Statement: The authors have no conflicts of interest to declare.

Financial Disclosure: This research was supported by the Scientific Research Projects Department of Yüzüncü Yll University. (Project No: 2015-VSYO-B257)

Author Contributions: All of the authors declare that they have all participated in the design, execution, and analysis of the paper, and that they have approved the final version.

\section{REFERENCES}

1. Bulduk B. Diabetes mellitus ve oral atidiyabetikler, C. (Ed). Evereklioğlu içinde, Sağlık Bilimlerinde Araştırma ve Değerlendirmeler 1. baskı, Ankara: Gece Kitaplığı; 2021.

2. Hung LM, Chen JK, Huang SS, Lee RS, Su MJ. Cardioprotective effect of resveratrol, a natural antioxidant derived from grapes. Cardiovasc Res 2000; 47: 549-55.

3. Arany I, Safirstein RL. Cisplatin nephrotoxicity. Semin Nephrol 2003; $23: 460-4$.

4. Astolfi L, Ghiselli S, Guaran V, et al. Correlation of adverse effects of cisplatin administration in patients affected by solid tumours: A retrospective evaluation Oncol Rep 2013; 29: 1285-92.

5. Yadav S, Vats V, Dhunnoo Y, Grover J.K. Hypoglycemic and antihyperglycemic activity of Murraya koenigii leaves in diabetic rats. J Ethnophamacol 2002; 82: 111-6.

6. Pari L, Latha L. Protective role of Scopari dulcis plant extract on brain antioxidant status and lipidperoxidation in STZ diabetic male wistar rats. BMC Compliment Altern Med 2004; 4:16-24.

7. Bulduk B, Kılınç D. Günlük Crataegus oxyacatha (Alıç) uygulamasının ratlarda EKG değerlerine etkisi. Yüzüncü Yıl Üniversitesi Veteriner Fakültesi Dergisi 2013; 24: 77-81.

8. Heydari I, Radi V, Razmjou S, Amiri A. Chronic complications of diabetes mellitus in newly diagnosed patients. Int J Diabetes Mellitus 2010; 2: 61-3.

9. Kikkawa R. Chronic complications in diabetes mellitus. Br J Nutr 2000; $2: 183-5$.
10.Susztak K, Raff AC, Schiffer M, Bottinger EP. Glucose- induced reactive oxygen species cause apoptosis of podocytes and podocytedepletion at the onset of diabetic nephropathy. Diabetes 2006; 55: 225-33.

11.Parker AB, Yusuf S, Naylor CD. The relevance of subgroup-specific treatment effects: the Studies of left ventricular dysfunction (SOLVD) revisited. Am Heart J 2002; 144: 941-7.

12. Kurçer Z, Karaoğlu D. Deneysel diyabet modellerinde alloksan ve streptozotosin kullanımı. Türk Jem 2012;16: 34-40.

13. Green A, Sjølie AK, Eshøj O. Trends in the epidemiology of IDDM during 1970-2020 in Fyn County, Denmark. Diabetes Care 1996;19: 801-6.

14. Kanter M, Aktas C, Erboga M. Protective effects of quercetin against apoptosis and oxidative stress in streptozotocin-induced diabetic rat testis. Food Chem Toxicol 2012; 50: 719-25.

15. Khaki A, Fathiazad F, Nouri M, Khaki A, Maleki NA, Khamnei HJ, Ahmadi P. Beneficial effects of quercetin on sperm parameters in streptozotocin-induced diabetic male rats. Phytother Res 2010; 24: 1285-91.

16. Sharma S, Anjeneyulu M, Kulkarni SK, Chopra K. Resveratrol, a polyphenolic phytoalexin, attenuates diabetic nephropathy in rats. Pharmacology 2006; 76: 69-75.

17.Su HC, Hung LM, and Chen JK. Resveratrol, a red wine antioxidant, possesses an insülin-like effect in streptozotocininduced diabetic rats. Am J Physiol Endocrinol Metab 2006; 290: 1339-46.

18. Chen KH, Hung CC, Hsu HH, Jing YH, Yang CW, Chen JK. Resveratrol ameliorates early diabetic nephropathy associated with suppression of augmented TGF- $\beta /$ smad and ERK1/2 signaling in streptozotocin-induced diabetic rats. Chemico Biological Interactions 2011;15: 45-53.

19. Tzong-Cherng C, Chen WP, Chi T-Li, et al. Phosphatidylinositol3-kinase is Involved in the antihyperglycemic effect induced by resveratrol in streptozotocin- induced diabetic rats. Life Sci 2007; 80: $1720-13$

20. Nihei T, Miura Y, Yagasaki K. Inhibitory effect of resveratrol on proteinuria, hypoalbuminnemia and hyperlipidemia in nephritic rats. Life Sci 2001; 68: 2845-52.

21.Chi TC, Chen WP, Chi TL, et al. Phosphatidylinositol-3-kinase is involved in the antihyperglycemic effect induced by resveratrol in streptozotocin-induced diabetic rats, Life Sci 2007; 80: 1713-20.

22. Işık A, Koca S. Behçet hastaliğinda total antioksidan cevap ve oksidatif stres. Frrat Üniversitesi Sağlık Bilimleri Derg 2006; 20: 415-21.

23. Rodrigo R, Bosco C. Oxidative stress and protective effects of polyphenols: comparative studies in human and rodent kidney. A review. Comp Biochem Physiol Part C: Toxicol Pharmacol 2006; 142: $317-27$

24. Kasdallah-Grissa A, Mornagui B, Aouani E, et al. Resveratrol, a red wine polyphenol, attenuates ethanol-induced oxidative stress in rat liver. Life Sci 2007; 20: 1033-9.

25. Mıkulskı D, Gornıak R, Molsklı M. A theoretical study of the structure-radical scavenging activity of trans-resveratrol analogues and cisresveratrol in gas phase and water environment. Eur J Med Chem 2010; 45: 1015-27.

26. Carrizzo A, Forte M, Damato A, et al. Antioxidant effects of resveratrol in cardiovascular, cerebral and metabolicdiseases. Food Chem Toxicol 2013; 61: 215-26.

27.Gambinı J, Ingles M, Olaso G, Lopez-Grueso R, Bonet-Costa V, Gimeno-Mallench L. Properties of Resveratrol: In vitro and in vivo studies about metabolism, bioavailability, and biological effects in animal models and humans. Oxid Med Cell Longev 2015; 2015: 837042

28.Leonard SS, Xia C, Jiang BH, et al. Resveratrol scavenges reactive oxygen species and effects radicalinduced cellular responses. Biochem Biophys Res Commun 2003; 309: 1017-26. 
29. Juhasz B, Varga B, Gesztelyi R, et al. Resveratrol: a multifunctional cytoprotective molecule. Curr Pharm Biotechnol 2010; 11: 810-8.

30. Bulduk M, Oto G, Ozdemir H, Demirel-Yilmaz E. The effect of resveratrol therapy on the vascular responses caused by chronic fluorosis. Fluoride 2020; 53: 23-39.

31.Pandey KB, Rizvi SI. Anti-oxidative action of resveratrol: Implications for human health, Arabian J. Chem 2010; 4: 293-6.

32.S Sehirli O, Tozan A, Omurtag GZ, et al. Protective effect of resveratrol against naphthalene-induced oxidative stress in mice. Ecotoxicol and Environ Saf 2008; 71: 301-8.

33. Yulug E, Türedi S, Karagüzel E, Kutlu O, Mentese A, Alver A. The short term effects of resveratrol on ischemia-reperfusion injury in rat testis. J Pediatr Surg 2014; 49: 484-9.

34. Bozkurt N. DMBA ile olușturulan rat karaciğer hasarında resveratrol ve pekmezin karaciğer enzimleri ve oksidatif stres parametreleri üzerine etkilerinin araștırılması. İnönü Üniversitesi Sağlık Bilimleri Enstitüsü Yüksek Lisans Tezi 2014

35. Juan ME, Vinardell MP, Planas JM. The daily oral administration of high doses of trans-resveratrol to rats for 28 days is not harmful. J Nutr 2002; 132: 257-60

36. Ghosh S, Bhattacharyya S, RashidK, Sil PC. Curcumin protects rat liver from streptozotocin-induced diabetic pathophysiology by counteracting reactive oxygen species and inhibiting the activation of p53 and MAPKs mediated stress response pathways." Toxicology Reports 2015; 2: 365-76.

37. Yousef MI, Saad AA, El-Shennawy LK. Protective effect of grape seed proanthocyanidin extract against oxidative stress induced by cisplatin in rats. Food Chem Toxicol 2009; 47 : 1176-83.

38. Alhaider AA, Korashy HM, Sayed-Ahmed MM, Mobark M, Kfoury H, Mansour MA. Metformin attenuates streptozotocininduced diabetic nephropathy in rats through modulation of oxidative stress genes expression. Chemico-Biological Interactions 2011; 192: 233-42.

39. Chirina YI, Jose PC. Sisplatin kaynaklı nefrotoksisitede oksidatif ve nitrozatif stresin rolü. Deneysel ve Toksikolojik Patoloji 2009; 61: 223-42.

40.Noyan A. Fizyoloji.8.baskı. Meteksan A.Ş. Ankara; 1993.

41.Schwartz PJ, Stramba-Badiale M, Segantini A, et al. Prolongation of the QT interval and the sudden infant death syndrome. New Engl J Med 1998; 11:1709-14.

42. Antselevitch C, Shimizu W. Cellular mechanisms underlying the long QT syndrome. Curr Opin Cardiol 2002; 17: 43-51.

43. Akıta M., Kuwahara M., Tsubone H., Sugano S. ECG changes during furosemide-induced hypokalemia in The rat. J Electrocardiol 1998; 31: 45-9.

44. Mackiewicz U, Gerges JY, Chu S, et al. Ivabradine protects against ventricular arrhythmias in acute myocardial infarction in the rat. J Cell Physiol 2014; 229: 813-23.

45. Hamdy Dalia A MSc; Brocks, Dion R PhD. Experimental hyperlipidemia causes an increase in the electrocardiographic changes associated with amiodarone. J Cardiovasc Pharmacol 2009; 53: 1-8.

46. Takahara A, Sugiyama A, Hashimoto K. Reduction of repolarization reserve by halothane anaesthesia sensitizes the guinea-pig heart for drug-induced QT interval prolongation. $\mathrm{Br}$ J Pharmacol 2005;146: 561-7.

47. Hashemzaei M, Barani AK, Iranshahi $M$, et al. Effects of resveratrol on carbon monoxide-induced cardiotoxicity in rats. Environ Toxicol Pharmacol 2016; 46:110-5.

48. Demrow HS, Slane PR, Folts JD. Administrator of wine and Grape juice inhibits in vivo platelet activity and trombosis in sterosed canine coronary arteries. Circulation 1995; 91:82-8.

49. Chen CK, Pace-Asciak CR. Vasorelaxing Activity of Resveratrol and Quercetin in Isolated Rat Aorta. Gen Pharmacol 1996; 27 363-6.
50. Wollny T, Aiello L, Tommaso DD, et al. Modulation of haemostatic function and prevention of experimental trombosis by red wine in rats: a role for increased nitric oxide production. B J Pharmacol 1999; 127: 747-55.

51.Stef G, Csiszar A, Lerea K, Ungvari Z, Veress G. Resveratrol inhibits aggregation of platelets from high-risk cardiac patients with aspirin resistance. J Cardiovasc Pharmacol 2006; 48: 1-5.

52.Buschmann G, Schumacher W, Budden R, Kühl UG. Evaluation of the effect of dopamine and othercatecholamines on the electrocardiogram and blood pressure of rats by means of on-line biosignal processing. J Cardiovasc Pharmacol 1980; 2: 777-95.

53. Ahmad A, Sattar MZ, Rathore HA, et al. Impact of Isoprenaline and Caffeine on development of left ventricular hypertrophy and renal hemodynamic in Wistar Kyoto rats. Acta Pol Pharm 2015;72: 1015-26

54. Vilar-Pereira G, Carneiro VC, Mata-Santos H, et al. Resveratrol reverses functional chagas heart disease in mice. PLoS pathogens 2016; 12: e1005947.

55.Kuzmin AI, Gourine AV, Molosh AI, Lakomkin VL, Vassort G. Effects of preconditioning on myocardial interstitial levels of ATP and its catabolites during regional ischemia and reperfusion in the rat. Basic Res Cardiol 2000; 95:127-36. 